\title{
Barrier-Lowering Effects of Baird Antiaromaticity in Photoinduced Proton-Coupled Electron Transfer (PCET) Reactions
}

\author{
Lucas J. Karas, ${ }^{*}$ Chia-Hua Wu, Judy I. Wu*
}

ABSTRACT: Baird antiaromaticity plays a central role in the photochemistry of proton-coupled electron transfer (PCET) reactions. We recognize that many popular organic chromophores that catalyze photoinduced PCET reactions are Hückel aromatic in the ground state, but gain significant Baird antiaromatic character in the lowest $\pi \pi^{*}$ state, having important barrier-lowering effects for electron transfer. Two examples, 1) the photolytic $\mathrm{O}-\mathrm{H}$ bond dissociation of phenol and 2) solar water splitting in the pyridine-water complex, are discussed. Contrary to an assumed homolytic $\mathrm{O}-\mathrm{H}$ bond dissociation, both reactions proceed through loss (and gain) of an electron in the $\pi$-system (i.e., antiaromaticity relief), followed by heterolytic cleavage of the polar O-H bond near barrierlessly. Nucleus-independent chemical shifts (NICS), ionization energies (IE), electron affinities (EA), and excited-state PCET energy profiles of selected $[4 n]$ and $[4 n+2] \pi$-systems are presented.

Photoinduced proton-coupled electron transfer (PCET) reactions are the critical steps to a myriad of energy conversion processes in organic photochemistry. ${ }^{1,2}$ In the case where an electron moves first, these reactions also can be called electron-driven proton transfer (EDPT) — an aromatic chromophore absorbs light, triggers the migration of an electron, and a proton follows. These reactions typically have low-barriers, and here, we make the connection between facile electron transfer and the concepts of ground and excited-state (anti)aromaticity. We note that the most common organic chromophores (e.g., phenol, ${ }^{3}$ pyridine, ${ }^{4}$ and other $\pi$-conjugated rings ${ }^{5,6}$ ) are $[4 n+2]$ Hückel aromatic in the ground state, ${ }^{7}$ but convert to $[4 n+2]$ Baird antiaromatic in the lowest $\pi \pi^{*}$ state, ${ }^{8}$ and the high-energy $\pi$ system can easily lose (or gain) an electron triggering the first step of a photoinduced PCET reaction.

A representative example is the photolytic $\mathrm{O}-\mathrm{H}$ bond fission of phenol. Flash photolysis and transient absorption studies of phenol in the vapor phase and in aqueous solution indicate the formation of neutral phenoxy radicals. ${ }^{9,10}$ According to ab initio studies and kinetic experiments, UV irradiation first generates an optically active $\pi \pi^{*}$ state, then $\mathrm{O}-\mathrm{H} \sigma$-bond fission resolves in a dark $\pi \sigma^{*}$ state, reached by nonadiabatic interaction of the two surfaces. ${ }^{5,11-13}$ It was reported for many other aromatic chromophores, that photolytic O-H or N$\mathrm{H}$ bond fission proceeded through similar dissociative charge transfer states. ${ }^{3,6,14}$ The net outcome of these reactions is $\sigma$-bond cleavage, but it is the $\pi$-ring that absorbs light.

Traditionally, the driving force for photoinduced electron transfer has been explained by the Rehm-Weller model, ${ }^{15}$ where Gibbs free energy for charge separation is estimated by the oxidation and reduction potential of the electron donor and acceptor, respectively. But here, we show that a more complete picture emerges when the effects of excited-state (anti)aromaticity are considered. A number of works have recognized the role of excited-state antiaromaticity in organic photoreactions (e.g., the photoionization of haloaromatic compounds, ${ }^{16}$ phototriggered bond breaking, ${ }^{17,18}$ photodeactivation of DNA base pairs, ${ }^{19}$ photoreaction of benzene, ${ }^{20}$ and excited-state proton transfer ${ }^{21,22}$ ).

In this paper, we demonstrate that Hückel aromatic chromophores can gain significant Baird antiaromatic character in the lowest $\pi \pi^{*}$ states, and the emergence of excited-state antiaromaticity catalyzes electron transfer. Our arguments are developed first based on a comparison of energy profile of the photoinduced PCET reactions of phenol, hydroxyl-cyclooctatetraene, and derivatives of these model systems in the $T_{1}$ state, followed by a detailed theoretical analysis of two photoinduced PCET reactions in the $S_{1}$ state: 1 ) the photolytic bond fission of phenol, and 2) solar water splitting from a pyridine-water complex.

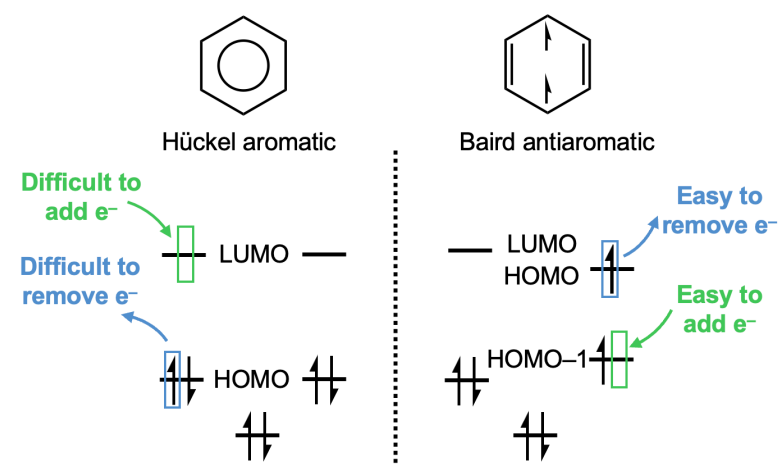

Scheme 1. Schematic illustration of frontier molecular orbitals of benzene in the $S_{0}$ (aromatic) and $T_{1}$ (antiaromatic) states.

Consider the frontier molecular orbital energies of benzene (Scheme 1). In the $S_{0}$ state, benzene is Hückel aromatic, there is a large orbital splitting between the degenerate set of highest occupied molecular orbitals (HOMO) and lowest unoccupied molecular orbitals (LUMO), and both removing an electron from the low-lying HOMO and adding an electron to the high-lying LUMO are energetically costly (Scheme 1 , left). But in the $T_{1}\left({ }^{3} \pi \pi^{*}\right)$ state, benzene 
is Baird antiaromatic and this is characterized by a small orbital splitting (i.e., Jahn-Teller distortion of the degenerate set of antibonding $\pi$-orbitals) ${ }^{23-26}$ Now the HOMO is a half-filled orbital belonging to a degenerate set of antibonding orbitals, and removing an electron from this high-lying orbital becomes easier. The HOMO-1, a lowlying bonding orbital, also readily accepts an electron (Scheme 1, right). In this way, aromaticity and antiaromaticity can be linked to the ease of removing or adding an electron to a $\pi$-system.

Computed ionization energies (IE) and electron affinities (EA) for toluene and methylenecyclohexadiene in the $S_{0}$ and $T_{1}$ states are illustrative. In the $S_{0}$ state, toluene is $[4 n+2]$ Hückel aromatic $\left(\operatorname{NICS}(1)_{z z}=-26.5 \mathrm{ppm}\right)$ and exhibits both a higher IE $(+8.8$ $\mathrm{eV})$ and a higher $\mathrm{EA}(+2.1 \mathrm{eV})$ compared to the nonaromatic isomer $(\mathrm{IE}=+7.7 \mathrm{eV}, \mathrm{EA}=+0.7 \mathrm{eV})$ (Figure $1 \mathrm{a}$, left). But in the $\mathrm{T}_{1}$ state, toluene is $[4 n+2]$ Baird antiaromatic $\left(\operatorname{NICS}(1)_{z z}=+38.7 \mathrm{ppm}\right)$ and displays both a lower IE $(+5.3 \mathrm{eV})$ and a lower EA $(-2.0 \mathrm{eV})$ compared to the $T_{1}$ state of the nonaromatic isomer $(\mathrm{IE}=+6.1 \mathrm{eV}, \mathrm{EA}=$ $-1.0 \mathrm{eV})$ (Figure 1a, right). Nucleus-independent chemical shifts, $\operatorname{NICS}(1)_{z z}$, were computed at $1 \AA$ above the ring centers including only the out-of-plane $(z z)$ tensor component. ${ }^{27-29}$ Negative $\operatorname{NICS}(1)_{z z}$ values indicate aromaticity and positive $\operatorname{NICS}(1)_{z z}$ values indicate antiaromaticity.

Computed IE and EA data for the $S_{0}$ and $T_{1}$ states of planar $[4 n]$ methyl-cyclooctatetraene (COT) and planar methylenecyclooctatriene show the opposite trend. Planar methyl-COT is $[4 n]$ Hückel antiaromatic (NICS $\left.(1)_{z z}=+35.5 \mathrm{ppm}\right)$, and exhibits both a lower IE $(+7.2 \mathrm{eV})$ and a lower EA $(-0.7 \mathrm{eV})$ compared to the nonaromatic isomer $(\mathrm{IE}=+7.7 \mathrm{eV}, \mathrm{EA}=+0.1 \mathrm{eV})$ (Figure $1 \mathrm{~b}$, left). But in the $\mathrm{T}_{1}$ state, methyl-COT is $[4 n]$ Baird aromatic $\left(\operatorname{NICS}(1)_{z z}=-24.1 \mathrm{ppm}\right)$ and displays a higher IE $(+6.8 \mathrm{eV})$ and a higher EA $(-1.0 \mathrm{eV})$ compared to that of the nonaromatic isomer $(\mathrm{IE}=+6.1 \mathrm{eV}, \mathrm{EA}=-1.5$ eV) (Figure 1b, right). Zhu and Schleyer have shown that isomerization energies of the $S_{0}$ and $T_{1}$ states of such pairs provide reliable energetic measures for ground and triplet state (anti)aromaticity. ${ }^{30}$ All geometries were optimized with a constrained $C_{S}$ symmetry, and energies were computed at CASPT2/6-311+G(d,p)//CASSCF/6$311+\mathrm{G}(\mathrm{d}, \mathrm{p})$ using Molpro $2012 .{ }^{31} \mathrm{NICS}(1)_{z z}$ for six-membered ring systems were computed at CASSCF $/ 6-311+\mathrm{G}(\mathrm{d}, \mathrm{p})$, and for eightmembered ring systems, at CASSCF/6-31G(d,p), using the Dalton 2016 program. ${ }^{32,33}$

Figure 2 compares the $\mathrm{T}_{1}$ state PCET energy profiles of 4-methyl-phenol $(1,[4 n+2])$ and 1-hydroxy-5-methyl-COT (2, [4n]) with that of their nonaromatic isomers (1' and 2'). Potential energy profiles along the $\mathrm{O}-\mathrm{H}$ stretching coordinate were computed at 0.1 Å intervals in the ${ }^{3} \pi \pi^{*}$ and ${ }^{3} \pi \sigma^{*}$ states (see Figure $S 4$ for the $S_{1}$ state results). As the $\mathrm{O}-\mathrm{H}$ bond stretches, the ${ }^{3} \pi \pi^{*}$ and ${ }^{3} \pi \sigma^{*}$ curves intersect and crossing of the two functions marks the point at which an electron transfers from the $\pi$-ring to the acidic $\mathrm{H}$ atom. Barriers to electron transfer $\left(\Delta E_{E T}\right)$ were estimated based on the energy measured at the crossing of the interpolated ${ }^{3} \pi \pi^{*}$ and ${ }^{3} \pi \sigma^{*}$ curves minus the energy of the ${ }^{3} \pi \pi^{*}$ at $\mathrm{O}-\mathrm{H}=1 \AA \AA .1$ (Baird antiaromatic) displays a high $\mathrm{T}_{1}$ state energy $(80.7 \mathrm{kcal} / \mathrm{mol})$ and the ${ }^{3} \pi \pi^{*}$ to ${ }^{3} \pi \sigma^{*}$ intersection occurs "early" through a relatively low barrier $\left(\Delta E_{E T}=27.3\right.$ $\mathrm{kcal} / \mathrm{mol}$, at $\mathrm{O}-\mathrm{H}=1.26 \AA$ ) (Figure 2a, left). In contrast, 1' (nonaromatic) exhibits a lower $T_{1}$ state energy $(38.3 \mathrm{kcal} / \mathrm{mol})$ and the conical intersection occurs "late" through a nearly doubled barrier $\left(\Delta E_{E T}\right.$
$=57.0 \mathrm{kcal} / \mathrm{mol}$, at $\mathrm{O}-\mathrm{H}=1.47 \AA$ ) (Figure 2b, left). Computed NICS $(1)_{z z}$ values for $\mathbf{1}$, at geometries along the photoinduced PCET pathway, show an abrupt drop in paratropicity past the ${ }^{3} \pi \pi^{*}$ to ${ }^{3} \pi \sigma^{*}$ intersection (Figure $2 \mathrm{a}$, right, note the sign change of NICS $(1)_{z z}$ values from positive to negative), while those of 1 ' remain constant for both the ${ }^{3} \pi \pi^{*}$ and ${ }^{3} \pi \sigma^{*}$ states, having values close to zero (Figure $3 b$, right). We recognized the high $T_{1}$ state energy of 1 as a consequence of Baird antiaromaticity, and facile electron transfer is the escape from it. a)<smiles>Cc1ccccc1</smiles>

Hückel

aromatic

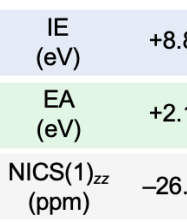

b)

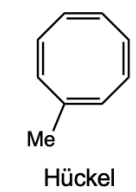

antiaromatic

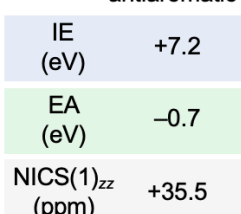

(ppm)

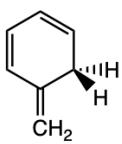

$\mathrm{CH}_{2}$
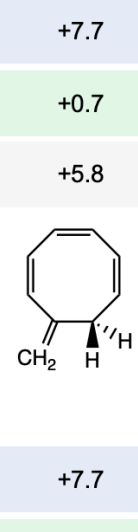

$+0.1$

$+1.8$
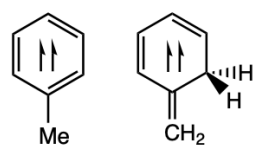

Baird

antiaromatic
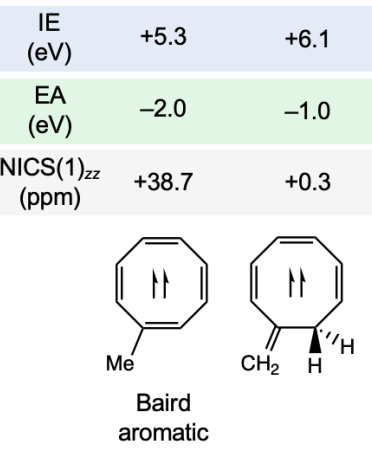

\begin{tabular}{ccc}
$\begin{array}{c}\mathrm{IE} \\
(\mathrm{eV})\end{array}$ & +6.8 & +6.1 \\
$\begin{array}{c}\mathrm{EA} \\
(\mathrm{eV})\end{array}$ & -1.0 & -1.5 \\
$\begin{array}{c}\mathrm{NICS}(1)_{\mathrm{zz}} \\
(\mathrm{ppm})\end{array}$ & -24.1 & +7.1 \\
\hline
\end{tabular}

Figure 1. Computed ionization energies (IE), electron affinities (EA), and NICS (1 $)_{z z}$ values of a) toluene vs. methylenecyclohexadiene, and b) planar methyl-COT vs. methylenecyclooctatriene, in the $S_{0}$ and $T_{1}$ states.

Potential energy profiles for the triplet states of $\mathbf{2}$ vs. 2' show the opposite trend. 2 (Baird aromatic) exhibits a low $\mathrm{T}_{1}$ state energy $(5.9 \mathrm{kcal} / \mathrm{mol})$ and crossing from the ${ }^{3} \pi \pi^{*}$ state to the ${ }^{3} \pi \sigma^{*}$ state involves a high barrier $\left(\Delta E_{E T}=69.5 \mathrm{kcal} / \mathrm{mol}\right.$, at $\left.\mathrm{O}-\mathrm{H}=1.56 \AA\right)$ due to a largely stabilized $\mathrm{T}_{1}$ state (Figure $2 \mathrm{c}$, left). In comparison, 2' (nonaromatic) has a higher $\mathrm{T}_{1}$ state energy $(31.5 \mathrm{kcal} / \mathrm{mol})$ and a lower barrier to electron transfer $\left(\Delta E_{E T}=56.5 \mathrm{kcal} / \mathrm{mol}\right.$, at $\mathrm{O}-\mathrm{H}=$ $1.47 \AA$ ) (Figure $2 \mathrm{~d}$, left, note the similar $\mathrm{T}_{1}$ energies and $\Delta E_{E T}$ values compared to 1', cf. Figure 2b). Computed NICS(1)zz values at geometries along the photoinduced PCET pathway of $\mathbf{2}$ show a sudden raise in paratropicity past the ${ }^{3} \pi \pi^{*}$ to ${ }^{3} \pi \sigma^{*}$ intersection (Figure $3 c$, right, note the sign change of $\operatorname{NICS}(1)_{z z}$ values from negative to positive), while those of 2' remain relatively constant for both the ${ }^{3} \pi \pi^{*}$ and ${ }^{3} \pi \sigma^{*}$ states (Figure $2 \mathrm{~d}$, right). Computed gauge-including magnetically induced current (GIMIC) $)^{34}$ plots, ${ }^{1} \mathrm{H}$ chemical shifts, and harmonic oscillator model of aromaticity (rHOMA) ${ }^{35}$ agree with NICS see data in the Supporting Information, SI). 

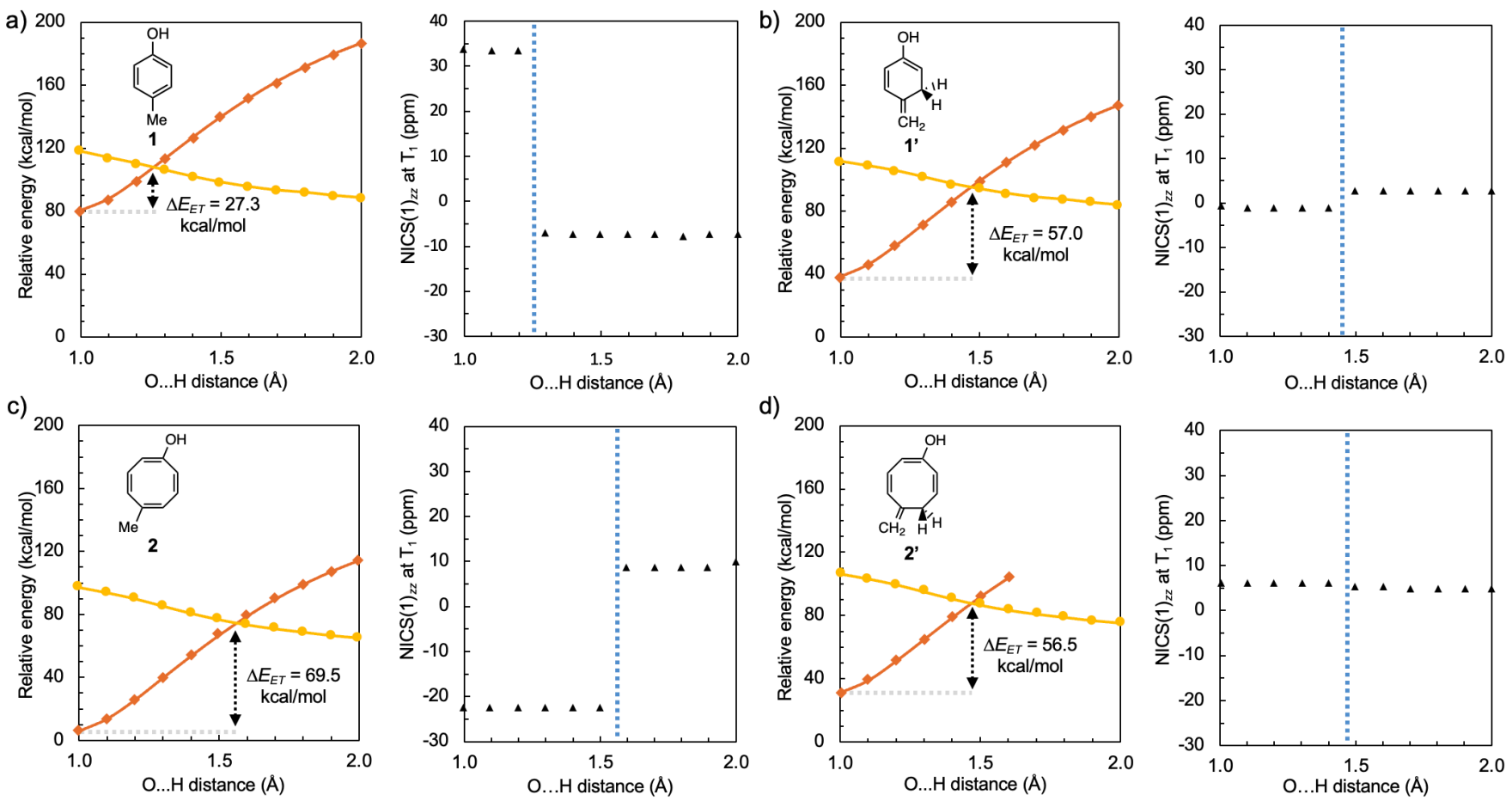

Figure 2. Computed potential energy profiles (in $\mathrm{kcal} / \mathrm{mol}$ ) along the $\mathrm{O}-\mathrm{H}$ stretching coordinate at $0.1 \AA$ intervals in the ${ }^{3} \pi \pi^{*}$ (orange rhomboids) and ${ }^{3} \pi \sigma^{*}$ (yellow circles) states for a) 1, b) 1', c) 2, and d) 2', and NICS $(1)_{z z}$ values (in ppm) computed along the photoinduced PCET pathway crossing the LE and CT states. In the NICS plots, the vertical blue dotted lines indicate crossing of the LE and CT states. All energies are relative to the $\mathrm{S}_{0}$ state energy at $\mathrm{O}-\mathrm{H}=1.0 \AA$.

Barrier-lowering effects of Baird antiaromaticity for photoinduced PCET reactions extend also to the $S_{1}$ state, ${ }^{36-39}$ in which reactions such as the photolysis of phenol take place. In the lowest ${ }^{1} \pi \pi^{*}$ state, phenol displays a low barrier to PCET $\left(\Delta E_{E T}=20.7 \mathrm{kcal} / \mathrm{mol}\right.$, at $\mathrm{O}-\mathrm{H}=1.21 \AA$, Figure $3 \mathrm{a})$ and computed NICS $(1)_{z z}$ values at geometries along the photoinduced PCET pathway show decreased paratropicity immediately past the intersection of the locally excited (LE) ${ }^{1} \pi \pi^{*}$ state and charge transfer (CT) ${ }^{1} \pi \sigma^{*}$ state (Figure $3 \mathrm{~b}$, see Figure $S 5$ for the $T_{1}$ results). The importance of the ${ }^{1} \pi \sigma^{*} \mathrm{CT}$ state has been recognized in earlier theoretical and experimental works, ${ }^{5,11}$ but here, we emphasize the mechanistic implications of this electron transfer step.

As shown in Figure 3c, the photolytic $\mathrm{O}-\mathrm{H}$ bond dissociation of phenol must happen heterolytically to give homolytic products (Figure 3c, bottom). Because the end products of the reaction are $\mathrm{H}^{\bullet}$ and a phenoxy radical $\left(\mathrm{PhO}^{\bullet}\right)$, it is tempting for the trained organic chemist to illustrate bond dissociation by two sets of singleheaded arrows showing homolytic cleavage of the $\mathrm{OH} \sigma$-bond (Figure $3 \mathrm{c}$, top). But the reaction cannot happen this way. The $>80$ $\mathrm{kcal} / \mathrm{mol}$ homolytic $\mathrm{O}-\mathrm{H}$ bond dissociation energy is much too high (note the parallel displaced $S_{0}$ and ${ }^{1} \pi \pi^{*}$ state curves)! Heterolytic cleavage of the polar $\mathrm{O}-\mathrm{H}$ bond requires much less energy (i.e., both electrons move towards the more electronegative $\mathrm{O}$ atom) and occurs readily upon crossing of the $\pi \pi^{*}$ and $\pi \sigma^{*}$ states. At the conical intersection, an electron moves away from the $\pi$-ring and the CT state $\left({ }^{1} \pi \sigma^{*}\right)$ is stabilized as the proton follows, giving the radical products. We note that closely related reactions such as the photoFries rearrangement of phenyl esters, also are commonly illustrated in Google searches and textbooks as homolytic O-R bond cleavage processes and suggest that the arrow pushing mechanisms of these reactions also ought to be redrawn. ${ }^{40,41}$
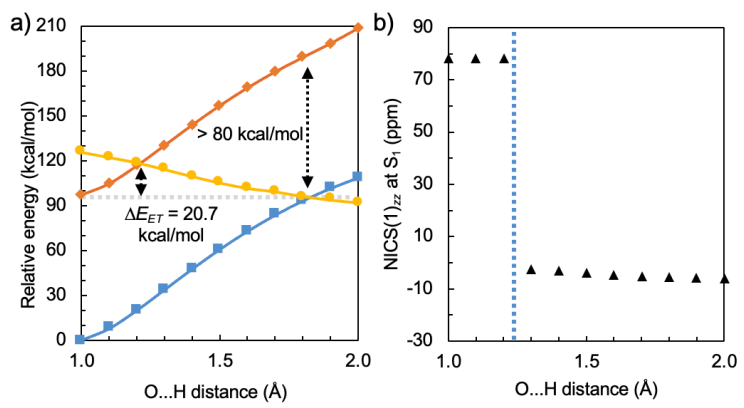

c)
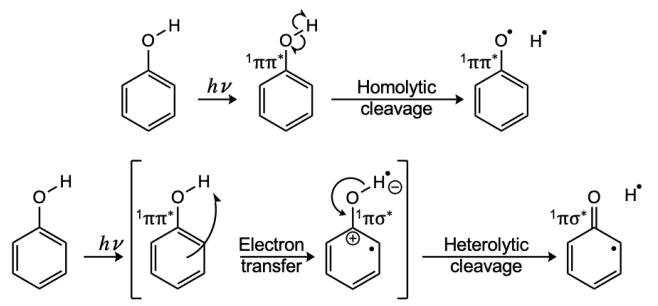

Figure 3. a) Computed potential energy profiles (in $\mathrm{kcal} / \mathrm{mol}$ ) along the $\mathrm{O}-\mathrm{H}$ stretching coordinate at $0.1 \AA$ intervals, in the $\mathrm{S}_{0}$ (blue squares), $\operatorname{LE}\left({ }^{1} \pi \pi^{*}\right.$, orange rhomboids), and $\mathrm{CT}\left({ }^{1} \pi \sigma^{*}\right.$, yellow circles) states for phenol, and b) NICS(1) $z z$ values (in ppm) computed along the photoinduced PCET pathway crossing the LE and $\mathrm{CT}$ states. All energies are relative to the $\mathrm{S}_{0}$ state energy at $\mathrm{O}-\mathrm{H}=1$ Å. c) Photoinduced homolytic vs. heterolytic O-H bond breaking mechanisms. 
We further considered the phototriggered water splitting reaction of a model pyridine (Py)-water complex. Photodeactivation through PCET was suggested as a reason for the absence of fluorescence of pyridine in water. ${ }^{4,42-46}$ Water splitting through this route requires two photons. In the first step, pyridine absorbs light $\left(\pi \pi^{*}, \mathrm{LE}\right.$ state), and an electron moves from water to the photoexcited $\pi$-ring followed by proton transfer $\left(\pi \pi^{*}\right.$ or $n \pi^{*}$, CT state), generating a $\mathrm{PyH}^{\bullet}$ and $\mathrm{OH}^{\bullet}$ radical pair. The triplet CT state is degenerate with the singlet state and can be reached through efficient intersystem crossing. Photoreactions on the excited singlet and triplet state surfaces were shown to be quite similar. In the next step, a second photon detaches $\mathrm{H}^{\bullet}$ from $\mathrm{PyH}^{\bullet}$ and regenerates the catalytic pyridine. Without the chromophore, homolytic bond cleavage of an $\mathrm{O}-\mathrm{H}$ bond in water (in the gas phase) is $5.1 \mathrm{eV} .{ }^{47}$ Here, we examine the first step of the reaction, showing that in the lowest $\pi \pi^{*}$ state the catalytic pyridine ring is Baird antiaromatic, and that adding an electron from water to the pyridine ring alleviates excited-state antiaromaticity.
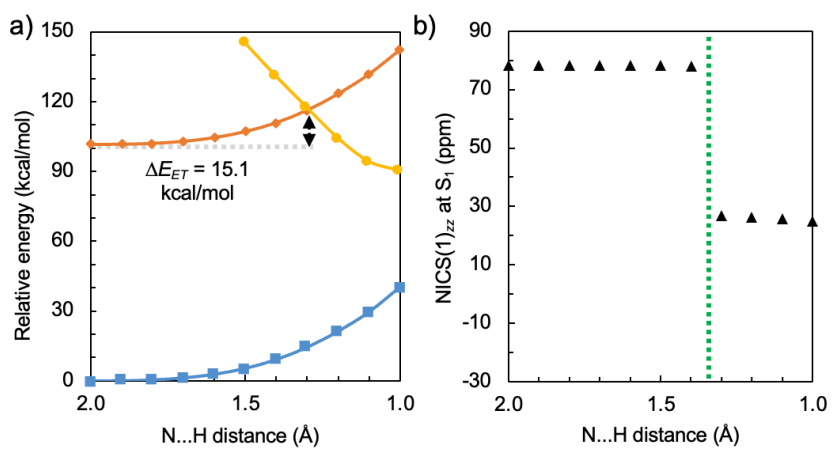

c)
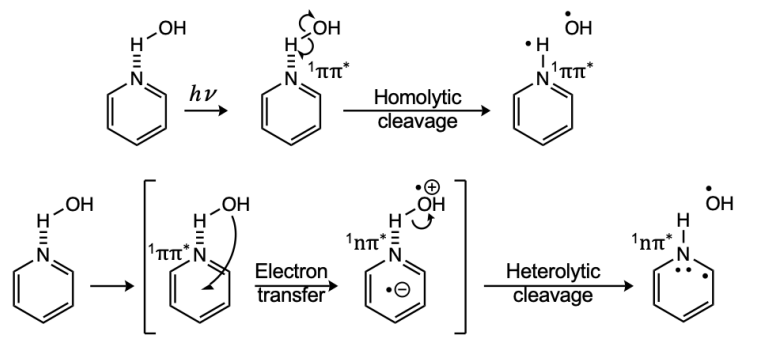

Figure 4. a) Computed potential energy profiles (in $\mathrm{kcal} / \mathrm{mol}$ ) along the $\mathrm{N}-\mathrm{H}$ bond forming coordinate at $0.1 \AA$ intervals, in the $\mathrm{S}_{0}$ (blue squares), $\operatorname{LE~}\left({ }^{1} \pi \pi^{*}\right.$, orange rhomboids), and CT ( ${ }^{1} n \pi^{*}$, yellow circles) states for the (Py)-water complex, and b) NICS $(1)_{z z}$ values (in ppm) computed along the photoinduced PCET pathway crossing the LE and CT states. All energies are relative to the $S_{0}$ state energy at $\mathrm{O}-\mathrm{H}=1 \AA$. c) Photoinduced homolytic vs. heterolytic $\mathrm{O}-\mathrm{H}$ bond breaking mechanisms.

Figure 4a shows the computed energy profiles of the (Py)-water complex at $0.1 \AA$ intervals along the $\mathrm{N}-\mathrm{H}$ bond forming coordinate (i.e., $\mathrm{H}$ moving from water to the pyridinyl $\mathrm{N}$ ) in the $\mathrm{S}_{0}$ state, LE state $\left({ }^{1} \pi \pi^{*}\right)$, and CT state $\left({ }^{1} n \pi^{*}\right.$, i.e., electron transfer from the hybridized lone pair of $\mathrm{O}$ to the pyridinyl ring). It was shown that crossing from the ${ }^{1} \pi \pi^{*} \mathrm{LE}$ state to the ${ }^{1} \pi \pi^{*} \mathrm{CT}$ state (i.e., electron transfer from the unhybridized lone pair of $\mathrm{O}$ to the pyridinyl ring) produced a similar energetic profile. ${ }^{4}$ As the $\mathrm{N}-\mathrm{H}$ bond forms, the $\mathrm{LE}$ and CT curves intersect and crossing of the two functions marks the point at which an electron transfers from water to the $\pi$-ring, and the water $\mathrm{O}-\mathrm{H}$ bond breaks heterolytically (Figure 4c). Note the low barrier to PCET $\left(\Delta E_{E T}=15.1 \mathrm{kcal} / \mathrm{mol}\right.$, at $\mathrm{N}-\mathrm{H}=1.29 \AA \mathrm{cf} .5 .1$ $\mathrm{eV}$ homolytic bond dissociation). Computed $\operatorname{NICS}(1)_{z z}$ values at geometries along the reaction pathway show a drop in paratropicity past the LE and CT state intersection (Figure 4b, see Figure S6 for the $\mathrm{T}_{1}$ results).

Even though all photoexcited molecules can be thought to be "unstable," the strong $\pi$-destabilizing effect of Baird antiaromaticity makes it a tremendously useful concept for designing photocatalytic chromophores and electron transfer reactions. We hypothesize that the highly positive excited-state reduction potentials of popular organic photoredox catalysts (e.g., acridine and acridium catalysts, 14 ring $\pi$-electrons $)^{48-53}$ may be in part attributed to Baird antiaromaticity.

\section{ASSOCIATED CONTENT}

\section{Supporting Information}

The Supporting Information is available free of charge on the ACS Publications website.

Optimized Cartesian coordinates, computed ${ }^{1} \mathrm{H}$ chemical shifts, rHOMA analyses, GIMIC plots, as well as NICS $(1)_{z z}$ and PCET energy profiles of $\mathbf{1}$ and $\mathbf{1}$ ' in the $S_{1}$ state, and phenol and (Py)-water in the $\mathrm{T}_{1}$ state are included along with a full methods section.

\section{AUTHOR INFORMATION}

\section{Corresponding Author}

Judy I. Wu - Department of Chemistry, University of Houston, Houston, Texas 77204, United States; orcid.org/0000-0003-0590-5290; Email: jiwu@central.uh.edu

Lucas J. Karas - Department of Chemistry, University of Houston, Houston, Texas 77204, United States; orcid.org/0000-0001-7970119X; Email: lucaskaras@gmail.com

\section{Authors}

Chia-Hua Wu - Department of Chemistry, University of Houston, Houston, Texas 77204, United States; orcid.org/0000-0001-68503024

\section{ACKNOWLEDGMENT}

JIW thanks the National Science Foundation (CHE-1751370), the National Institute of General Medical Sciences of the National Institute of Health (R35GM133548), and the Alfred P. Sloan Research Foundation (FG-2020-12811) for support. We acknowledge the use of the Sabine cluster and support from the Research Computing Data Core at the University of Houston. Particularly, we thank Professor Henrik Ottosson for helpful suggestions for improving the manuscript.

\section{REFERENCES}

(1) Weinberg, D. R.; Gagliardi, C. J.; Hull, J. F.; Murphy, C. F.; Kent, C. A.; Westlake, B. C.; Paul, A.; Ess, D. H.; McCafferty, D. G.; Meyer, T. J. Protoncoupled electron transfer. Chem. Rev. 2012, 112, 4016-4093.

(2) Gagliardi, C. J.; Westlake, B. C.; Kent, C. A.; Paul, J. J.; Papanikolas, J. M.; Meyer, T. J. Integrating proton coupled electron transfer (PCET) and excited states. Coord. Chem. Rev. 2010, 254, 2459-2471. 
(3) Domcke, W.; Sobolewski, A. L. Unraveling the molecular mechanism of photoacidity. Science, 2003, 302, 1693-1694.

(4) Liu, X.; Sobolewski, A. J.; Borrelli, R.; Domcke, W. Computational investigation of the photoinduced homolytic dissociation of water in the pyridine-water complex. Phys. Chem. Chem. Phys. 2013, 15, 5957-5966.

(5) Ashfold, M. N. R.; Cronin, B.; Devine, A. L.; Dixon, R. N.; Nix, M. G. $D$. The role of $\pi \sigma^{*}$ excited states in the photodissociation of heteroaromatic molecules. Science, 2006, 312, 1637-1640.

(6) Sobolewski, A. L.; Domcke, W. Computational studies of the photophysics of hydrogen-bonded molecular systems. J. Phys. Chem. A 2007, 111, 11725-11735.

(7) Hückel, E. Z. Quantentheoretische beiträge zum benzolproblem. 1932, 70, 204-286.

(8) Baird, N. C. Quantum organic photochemistry: II. Resonance and aromaticity in the lowest ${ }^{3} \pi \pi^{*}$ state of cyclic hydrocarbons. J. Am. Chem. Soc. 1972, 94, 4941-4948.

(9) Land, E. J.; Porter, G. Primary photochemical processes in aromatic molecules. Part. 7.- spectra and kinetics of some phenoxyl derivatives. Trans. Faraday Soc., 1963, 59, 2016-2026

(10) G. Dobson, L. I. Grossweiner. Flash photolysis of aqueous phenol and cresols. Trans. Faraday Soc., 1965, 61, 708-714.

(11) Sobolewski, A. L.; Domcke W. Photoinduced electron and proton transfer in phenol and its clusters with water and ammonia. J. Phys. Chem. A 2001, 105, 9275-9283.

(12) Sobolewski, A. L.; Domcke, W.; Dedoner-Lardeux, C.; Jouvet, C. Excited-state hydrogen detachment and hydrogen transfer driven by repulsive ${ }^{1} \pi \sigma^{*}$ states: a new paradigm for nonradiative decay in aromatic biomolecules. Phys. Chem. Chem. Phys. 2002, 4, 1093-1100.

(13) Nix, M. G. D.; Devine, A. L.; Cronin, B.; Dixon, R. N. Ashfold, M. N. R. High resolution photofragment translational spectroscopy studies of the near ultraviolet photolysis of phenol. J. Chem. Phys. 2006, 125, 133318.

(14) Ashfold, M. N. R.; King, G. A.; Murdock, D.; Nix, M. G. D.; Oliver, T. A. A.; Sage, A. G. $\pi \sigma^{*}$ excited states in molecular photochemistry. Phys. Chem. Chem. Phys. 2010, 12, 1218-1238.

(15) Rehm, D.; Weller, A. Kinetics of fluorescence quenching by electron and $\mathrm{H}$-atom transfer. Isr. J. Chem. 1970, 8, 259-271.

(16) Jorner, K.; Rabten, W.; Slanina, T.; Vedin, N. P.; Sillén, Ludvigsson, J. W.; Ottosson, H.; Norrby, P.-O. Degradation of pharmaceuticals through sequential photon absorption and photoionization in amiloride derivatives. Cell Rep. Phys. Sci. 2020, 1, 100274.

(17) Halder, D.; Paul, A. Understanding the role of aromaticity and conformational changes in bond dissociation processes of photo-protecting groups. J. Phys. Chem. A 2020, 124, 3976-3983.

(18) Banerjee, A.; Halder, D.; Ganguly, G.; Paul, A. Deciphering the cryptic role of a catalytic electron in a photochemical bond dissociation using excited state aromaticity markers. Phys. Chem. Chem. Phys. 2016, 18, 25308 25314.

(19) Karas, L. J.; Wu, C.-H.; Ottosson, H.; Wu, J. I. Electron-driven proton transfer relieves excited-state antiaromaticity in photoexcited DNA base pairs. Chem. Sci. 2020, 11, 10071-10077.

(20) Slanina, T.; Ayub, R.; Toldo, J.; Sundell, J.; Rabten, W.; Nicaso, M.; Alabugin, I.; Galvan, I. F.; Gupta, A. K.; Lindh, R.; Orthaber, A.; Lewis, R. J.; Grönberg, G.; Bergman, J.; Ottosson, H. Impact of excited-state antiaromaticity relief in a fundamental benzene photoreaction leading to substituted bicyclo[3.1.0] hexenes. J. Am. Chem. Soc. 2020, 142, 10942-10954.

(21) Wu, C.-H.; Karas, L. J.; Ottosson, H.; Wu, J. I. Excited-state proton transfer relieves antiaromaticity in molecules. Proc. Natl. Acad. Sci. USA 2019, 116, 20303-20308.

(22) Lampkin, B. J.; Nguyen, Y. H.; Karadakov, P. B.; VanVeller, B. Demonstration of Baird's rule complementarity in the singlet state with implications for excited-state intramolecular proton transfer. Phys. Chem Chem. Phys. 2019, 21, 11608-11614.

(23) Ottosson, H. Exciting excited-state aromaticity. Nat. Chem. 2012, 4, 969-971.
(24) Rosenberg, M.; Dahlstrand, C.; Kilså, K.; Ottosson, H. Excited state aromaticity and antiaromaticity: opportunities for photophysical and photochemical rationalizations. Chem. Rev. 2014, 114, 5379-5425.

(25) Papadakis, R.; Ottosson, H. The excited state antiaromaticity benzene ring: a molecular Mr Hyde? Chem. Soc. Rev. 2015, 44, 6472-6493.

(26) Slanina, T.; Ayub, R.; Toldo, J.; Sundell, J.; Rabten, W.; Nicaso, M.; Alabugin, I.; Galván, I. F.; Gupta, A. K.; Lindh, R.; Orthaber, A.; Lewis, R. J.; Grönberg, G.; Bergman, J.; Ottosson, H. Impact of excited-state antiaromaticity relief in a fundamental benzene photoreaction leading to substituted bicyclo[3.1.0] hexenes. J. Am. Chem. Soc. 2020, 142, 10942-10954.

(27) Corminboeuf, C.; Heine, T.; Seifert, G.; Schleyer, P. v. R. Induced magnetic field in aromatic [n]-annulenes-interpretation of NICS tensor components. Phys. Chem. Chem. Phys. 2004, 6, 273-276.

(28) Chen, Z.; Wannere, C. S.; Corminboeuf, C.; Puchta, R.; Schleyer, P. v. R. Nucleus-independent chemical shifts (NICS) as an aromaticity criterion. Chem. Rev. 2005, 105, 3842-3888.

(29) Gogonea, V.; Schleyer, P. v. R.; Schreiner, P. R. Consequences of triplet aromaticity in $4 n \pi$-electron annulenes: calculation of magnetic shieldings for open-shell species. Angew. Chem. Int. Ed. 1998, 37, 1945-1948.

(30) Zhu, J.; An, K.; Schleyer, P. v. R. Evaluation of triplet aromaticity by the isomerization stabilization energy. Org. Lett. 2013, 15, 2442-2445.

(31) Werner, H.-J.; Knowles, P. J.; Knizia, G.; Manby, F. R.; Schütz, M. Molpro: a general-purpose quantum chemistry program. WIREs Comput. Mol. Sci. 2012, 2, 242-245.

(32) Aidas, K.; Angeli, C.; Bak, K. L.; Bakken, V.; Bast, R.; Boman, L.; Christiansen, O.; Cimiraglia, R.; Coriani, S.; Dahle, P.; Dalskov, E. K.; Ekström, U.; Enevoldsen, T.; Eriksen, J. J.; Ettenhuber, P.; Fernández, B.; Ferrighi, L.; Fliegl, H.; Frediani, L.; Hald, K.; Halkier, A.; Hättig, C.; Heiberg, H.; Helgaker, T.; Hennum, A. C.; Hettema, H.; Hjertenæs, E.; Høst, S.; Høyvik, I.-M.; Iozzi, M. F.; Jansik, B.; Jensen, H. J. A.; Jonsson, D.; Jørgensen, P.; Kauczor, J.; Kirpekar, S.; Kjærgaard, T.; Klopper, W.; Knecht, S.; Kobayashi, R.; Koch, H.; Kongsted, J.; Krapp, A.; Kristensen, K.; Ligabue, A.; Lutnæs, O. B.; Melo, J. I.; Mikkelsen, K. V.; Myhre, R. H.; Neiss, C.; Nielsen, C. B.; Norman, P.; Olsen, J.; Olsen, J. M. H.; Osted, A.; Packer, M. J.; Pawlowski, F.; Pedersen, T. B.; Provasi, P. F.; Reine, S.; Rinkevicius, Z.; Ruden, T. A.; Ruud, K.; Rybkin, V. V.; Salek, P.; Samson, C. C. M.; de Merás, A. S.; Saue, T.; Sauer, S. P. A.; Schimmelpfennig, B.; Sneskov, K.; Steindal, A. H.; Sylvester-Hvid, K. O.; Taylor, P. R.; Teale, A. M.; Tellgren, E. I.; Tew, D. P.; Thorvaldsen, A. J.; Thøgersen, L.; Vahtras, O.; Watson, M. A.; Wilson, D. J. D.; Ziolkowski, M.; Ågren, H. The Dalton quantum chemistry program system. WIREs Comput. Mol. Sci. 2013, 4, 269284.

(33) Dalton, a molecular electronic structure program, Release v2016.2 (2017), see http://daltonprogram.org

(34) Fliegl, H.; Taubert, S.; Lehtonen, O.; Sundholm, D. The gauge including magnetically induced current method. Phys. Chem. Chem. Phys. 2011, 13, 20500-20518.

(35) Krygowski, T. M. Crystallographic studies of inter- and intramolecular interactions reflected in aromatic character of $\pi$-electron systems. $J$. Chem. Inf. Comput. Sci. 1993, 33, 70-78.

(36) Aihara, J.-I. Aromaticity-based theory of pericyclic reactions. Bull. Chem. Soc. Jpn. 1978, 51, 1788-1792.

(37) Karadakov, P. B. Ground- and excited-state aromaticity and antiaromaticity in benzene and cyclobutadiene. J. Phys. Chem. A 2008, 112, 73037309.

(38) Karadakov, P. B. Aromaticity and antiaromaticity in the low-lying electronic states of cyclooctatetraene. J. Phys. Chem. A 2008, 112, 1270712713.

(39) Karadakov, P. B.; Hearnshaw, P.; Horner, K. E. Magnetic shielding, aromaticity, and bonding in the low-lying electronic states of benzene and cyclobutadiene. J. Org. Chem. 2016, 81, 11346-11352.

(40) Turro, N. J.; Ramamurthy, V.; Scaiano, J. C. Modern molecular photochemistry of organic molecules. University Science Books:Sausalito, CA. 2010, 1084pp. 
(41) Fries rearrangement. http://en.wikipedia.org/wiki/Fries_rearrangement, accessed March 22, 2021.

(42) Reimers, J. R.; Cai, Z.-L. Hydrogen bonding and reactivity of water to azines in their $S_{1}\left(n, \pi^{*}\right)$ electronic excited states in the gas phase and in solution. Phys. Chem. Chem. Phys. 2012, 14, 8791-8802.

(43) Liu, X.; Sobolewski, A. L.; Borrelli, R.; Domcke, W. Computational investigation of the photoinduced homolytic dissociation of water in the pyridine-water complex. Phys. Chem. Chem. Phys. 2013, 15, 5957-5966.

(44) Liu, X.; Sobolewski, A. L.; Domcke, W. Photoinduced oxidation of water in the pyridine-water complex: comparison of the singlet and triplet photochemistries. J. Phys. Chem. A 2014, 118, 7788-7795.

(45) Esteves-López, N.; Coussan, S.; Dedonder-Lardeux, C.; Jouvet, C. Photoinduced water splitting in pyridine water clusters. Phys. Chem. Chem. Phys. 2016, 18, 25637-25644.

(46) Pang, X.; Jiang, C.; Xie, W.; Domcke, W. Photoinduced electrondriven proton transfer from water of an $\mathrm{N}$-heterocylic chromophore: nonadiabatic dynamics studies for pyridine-water clusters. Phys. Chem. Chem. Phys. 2019, 21, 14073-14079.

(47) Maksyutenko, P.; Rizzo, T. R.; Boyarkin, O. V. A direct measurement of the dissociation energy of water. J. Chem. Phys. 2006, 125, 181101.

(48) Romero, N. A.; Margrey, K. A.; Tay, N. E.; Nicewics, D. A. Site-selective arene C-H amination via photoredox catalysis. Science, 2015, 249, 13261330.

(49) Liu, X.; Karsili, T. N. V.; Sobolewski, A. L.; Domcke, W. Photocatalytic water splitting with the acridine chromophore: a computational study. J. Phys. Chem. B 2015, 119, 10664-10672.

(50) McManus, J. B.; Nicewicz, D. A. Direct C-H cyanation of arenes via organic photoredox catalysis. J. Am. Chem. Soc. 2017, 139, 2880-2883.

(51) Tay, N. E. S.; Nicewicz, D. A. Cation radical accelerated nucleophilic aromatic substitution via organic photoredox catalysis. J. Am. Chem. Soc. 2017, 139, 16100-16104.

(52) Dang, H. T.; Haug, G. C.; Nguyen, V. T.; Vuong, N. T. H.; Nguyen, V. D.; Arman, H. D.; Larionov, O. V. Acridine photocatalysis: insights into the mechanism and development of a dual-catalytic direct decarboxylative conjugate addition. ACS Catal. 2020, 10, 11448-11457.

(53) Nguyen, V. T.; Nguyen, V. D.; Haug, G. C.; Vuong, N. T. H.; Dang, H. T.; Arman, H. D.; Larionov, O. V. Visible-light-enabled direct decarboxylative N-alkylation. Angew. Chem. Int. Ed. 2020, 59, 7921-7927. 